\title{
EMULSIFYING PROPERTIES OF AFZELIA GUM IN LIQUID PARAFFIN EMULSION
}

\author{
EMMANUEL O. OLORUNSOLA*, STEPHEN O. MAJEKODUNMI
}

Department of Pharmaceutics and Pharmaceutical Technology, University of Uyo, Uyo, Nigeria

Email: olorunsolaeo@yahoo.com

Received: 04 Aug 2016 Revised and Accepted: 09 Sep 2016

\begin{abstract}
Objective: Afzelia africana gum has been shown to possess surface activity. It is a good alternative to sodium carboxy methylcellulose in terms of suspending properties. This work was aimed at evaluating the emulsifying properties of the gum in liquid paraffin emulsion.

Methods: Liquid paraffin emulsions (200 ml each) were prepared with different concentrations $(1,2,3,5$ and $10 \%$ w/v) of afzelia gum as an emulsifying agent. Similar preparations containing standard acacia gum at corresponding concentrations were also made. Liquid paraffin emulsions (200 ml each) were equally prepared using $60 \mathrm{ml}$ liquid paraffin as the oily phase and $6 \mathrm{~g}$ of various combinations of afzelia gum and tween 80 as emulsifier blends. The emulsifier blends were of ratio 1:5, 1:2, 1:1, 2:1 and 5:1. The preparations were assessed for density and viscosity; and then for stability after $5 \mathrm{~d}$ of storage.
\end{abstract}

Results: The viscosity of emulsion containing $10 \% \mathrm{w} / \mathrm{v}$ afzelia gum was $668.90 \mathrm{mPa}$.s while that of an emulsion containing the same concentration of acacia gum was $23.56 \mathrm{mPa}$. s. Emulsion containing $3 \% \mathrm{w} / \mathrm{v}$ afzelia gum (having a creaming index of $16 \%$ ) was found to be more stable compared to the emulsion containing $10 \% \mathrm{w} / \mathrm{v}$ acacia gum (having creaming index of $28 \%$ ). The viscosity and stability of emulsions containing emulsifier blends of afzelia gum and tween 80 increased with increase in the proportion of afzelia gum.

Conclusion: The gum is suitable for use at a concentration of $3 \% \mathrm{w} / \mathrm{v}$ as an emulsifier in $30 \% \mathrm{v} / \mathrm{v}$ liquid paraffin emulsion, and it is about three times better than acacia gum as an emulsifier. It is a good alternative to standard acacia gum for emulsification.

Keywords: Afzelia gum, Liquid paraffin, Emulsifying properties, Density, Viscosity, Creaming

(C) 2016 The Authors. Published by Innovare Academic Sciences Pvt Ltd. This is an open access article under the CC BY license (http://creativecommons.org/licenses/by/4. 0/) DOI: http://dx.doi.org/10.22159/ijpps.2016v8i11.14509

\section{INTRODUCTION}

Liquid preparations, apart from being the only means by which certain medicinal agents can be delivered, are very useful means of administration of drugs to children under the age of $5 \mathrm{y}$ and for patients who have difficulty in swallowing [1]. These delivery systems include solutions, suspensions, and emulsions. They all have the advantage of fast delivery of medicaments, masking of disagreeable tastes and ease of dose adjustment. Therefore, they are important delivery systems. Suspensions and emulsions have the added advantage of the possibility of modifying drug release and duration of action [2].

A pharmaceutical emulsion is usually made up of the aqueous phase, the oily phase and an emulsifying system [3]. An emulsion could be oilin-water or water-in-oil depending on which phase is the dispersed and which one is continuous. It is also possible to have a multiple emulsion as oil-in-water-in-oil or water-in-oil-in-water. Emulsions of high viscosity for topical application are called creams and are of semisolid consistency. Hence, the choice of an emulsifying agent depends largely on its emulsifying properties, the type of emulsion to be formulated and the use of the final product [2].

Afzelia africana (family: Fabaceae) is widely distributed in Africa, and its gum is hemicellulose [4]. Physico-surface characterization of the gum showed that it has a critical micelle concentration of $0.25 \%$ $\mathrm{w} / \mathrm{v}$, HLB value of 9.74 and capable of reducing the surface tension of water from 72.00 to $69.00 \mathrm{~N} / \mathrm{m}$ at its critical micelle concentration [5]. The gum has been evaluated for its suspending properties by Okorie et al. [6]. It was found that binary combination of afzelia gum and sodium carboxymethyl cellulose in equal proportions brought forth better-suspending properties (rheological property and degree of flocculation) compared to the same concentration of the individual agent. Natural gums are generally useful as suspending and emulsifying agents [7].

Liquid paraffin is a mineral oil that is normally formulated as oil-inwater emulsion [8]. Natural gums stabilize this type of emulsion by forming a strong multi-molecular film round each oil globule so that coalescence is retarded by the presence of the hydrophilic barrier between the oily phase and the aqueous phase. Oil-in-water emulsion type has a lot of applications in drug delivery. For examples, fats and oils for oral administration either as a medicament or as a vehicle for oil-soluble drugs are formulated as oil-in-water emulsions. Emulsions for intravenous administration must be the oil-in-water type. Also, water-soluble drugs for topical application are formulated as oil-in-water emulsions [2].

Afzelia gum has been shown to be surface active [5] and to be useful as a suspending agent [6]. However, its use as an emulsifying agent was not obtainable from available literature. This study was aimed at evaluating the emulsifying properties of the gum in liquid paraffin emulsion.

\section{MATERIALS AND METHODS}

\section{Materials}

Materials used include: liquid paraffin, tween 80 and acacia gum (BDH Chemicals, England), purified water prepared at processing laboratory of Department of Pharmaceutics and Pharmaceutical Technology of University of Uyo, Uyo-Nigeria; and afzelia gum extracted from Afzelia africana seeds [5].

Preparation of liquid paraffin emulsions with different concentrations of gum

Liquid paraffin emulsions $(200 \mathrm{ml})$ were prepared with different concentrations of afzelia gum and acacia gum based on the formula in table1. The appropriate amount of the gum was weighed and transferred into a stainless steel container. Liquid paraffin $(60 \mathrm{ml})$ was measured and added to the gum inside the container. This was triturated together. A $40 \mathrm{ml}$ portion of purified water was measured and added to the oil/gum mixture. Emulsification was achieved by mixing the system for 5 min using a homogenizer (Silversons Machine Ltd., England) to obtain the primary emulsion [9]. The preparation was made to $200 \mathrm{ml}$ and homogenized for further $5 \mathrm{~min}$. 
Table 1: Formula for emulsions containing different gum concentrations

\begin{tabular}{|c|c|c|c|c|c|c|}
\hline \multirow[t]{2}{*}{ S. No. } & \multirow[t]{2}{*}{ Ingredients } & \multicolumn{5}{|c|}{ Batches } \\
\hline & & I & II & III & IV & V \\
\hline 1 & Liquid paraffin (\% v/v) & 30 & 30 & 30 & 30 & 30 \\
\hline 2 & Gum $(\% \mathrm{w} / \mathrm{v})$ & 1 & 2 & 3 & 5 & 10 \\
\hline 3 & Water to $(\%)$ & 100 & 100 & 100 & 100 & 100 \\
\hline
\end{tabular}

\section{Preparation of liquid paraffin emulsions with emulsifier blends}

Oil-in-water emulsions $(200 \mathrm{ml})$ were prepared using $60 \mathrm{ml}$ liquid paraffin as the oily phase and $6 \mathrm{~g}$ of various combinations of Afzelia africana gum and tween 80 as emulsifier blends based on table 2 . The emulsifier blends were of ratio 1:5, 1:2, 1:1, 2:1 and 5:1.
The appropriate quantity of the gum was weighed and distributed in the oily phase contained in a stainless steel cup. The calculated quantity of tween 80 was measured, diluted with $60 \mathrm{ml}$ of purified water and then triturated with the oily phase. The volume was made up to $200 \mathrm{ml}$ with purified water. Emulsification was effected by mixing each preparation for 5 min using a homogenizer (Silversons Machine Ltd., England).

Table 2: Formula for emulsions containing emulsifier blends

\begin{tabular}{|c|c|c|c|c|c|c|}
\hline \multirow[t]{2}{*}{ S. No. } & \multirow[t]{2}{*}{ Ingredients } & \multicolumn{5}{|c|}{ Batches } \\
\hline & & I & II & III & IV & $\mathbf{V}$ \\
\hline 1 & Liquid paraffin (ml) & 60 & 60 & 60 & 60 & 60 \\
\hline 2 & Gum (g) & 1 & 2 & 3 & 4 & 5 \\
\hline 3 & Tween 80 (g) & 5 & 4 & 3 & 2 & 1 \\
\hline 4 & Water to $(\mathrm{ml})$ & 200 & 200 & 200 & 200 & 200 \\
\hline
\end{tabular}

\section{Evaluation of emulsions}

\section{Determination of density}

The densities of the different emulsions were determined by weighing a specific volume of the emulsions $(20 \mathrm{ml})$. The mass $(\mathrm{g})$ obtained was divided by the volume of the emulsion.

\section{Determination of viscosity}

The viscosities of the different emulsions were determined at 27.4 ${ }^{\circ} \mathrm{C}$ using a viscometer (Brookfield NDJ-5S Digital viscometer), model LVF (with spindle $\#_{2}$ ) at $30 \mathrm{rpm}$.

\section{Assessment of stability}

The emulsions were examined for both cracking and creaming. A 50 $\mathrm{ml}$ volume of each preparation was transferred into $50 \mathrm{ml}$ capacity cylinder and left for $5 \mathrm{~d}$. The stability of each preparation was determined on the basis of coalescence or creaming. For creaming, the volume of the separated layer was determined and the percentage creaming was calculated as:

$$
\% \text { crea min } g=\frac{\text { Amount creamed }(\mathrm{ml})}{\text { Total volume }(\mathrm{ml})} X 100 \%
$$

\section{Data analysis}

Data analysis was done using one-way analysis of variance followed by Turkey-Kramer multiple comparison tests using Graph Pad Instat-3 software. Differences were taken as significant at $p$-values less than 0.05 .

\section{RESULTS}

The densities of liquid paraffin emulsions containing different concentrations of acacia and afzelia gums are shown in table 3. There was no significant difference in the density of emulsions containing different concentrations of acacia gum neither was there any significant difference in the density of emulsions containing different concentrations of afzelia gum. Also, there was no significant difference in the density of emulsions containing similar concentrations of acacia gum and afzelia gum.

Table 3: Densities of liquid paraffin emulsions containing different gum concentrations

\begin{tabular}{|c|c|c|}
\hline \multirow[t]{2}{*}{ Gum conc. $(\% \mathrm{w} / \mathrm{v})$} & \multicolumn{2}{|c|}{ Density of emulsion $\left(\mathrm{g} / \mathrm{cm}^{3}\right)$} \\
\hline & Acacia gum & Afzelia gum \\
\hline 1 & $1.06 \pm 0.02^{\mathrm{a}}$ & $1.00 \pm 0.02^{\mathrm{a}}$ \\
\hline 2 & $1.07 \pm 0.03^{\mathrm{a}}$ & $1.04 \pm 0.01^{\mathrm{a}}$ \\
\hline 3 & $1.07 \pm 0.02^{\mathrm{a}}$ & $1.04 \pm 0.02^{\mathrm{a}}$ \\
\hline 5 & $1.08 \pm 0.01^{\mathrm{a}}$ & $1.04 \pm 0.04 \mathrm{a}$ \\
\hline 10 & $1.10 \pm 0.02^{\mathrm{a}}$ & $1.05 \pm 0.02^{\mathrm{a}}$ \\
\hline
\end{tabular}

$\mathrm{N}=3$, Results are expressed as mean \pm SEM, For each column, same letter code means no significant difference at $p<0.05$.

The viscosities of liquid paraffin emulsions containing different concentrations of acacia and afzelia gums are shown in table 4 . There was no significant difference in the viscosity of emulsions containing $1-5 \% \mathrm{w} / \mathrm{v}$ of acacia gum and their values were significantly lower than the viscosity of emulsion containing $10 \% \mathrm{w} / \mathrm{v}$ of the gum. There was a significant difference in the viscosity of emulsions containing different concentrations of afzelia gum and the viscosity increased with increase in the concentration of the gum. The viscosity of emulsion containing afzelia gum was significantly higher than that containing acacia gum at all the concentrations used.

Table 4: Viscosities of liquid paraffin emulsions containing different gum concentrations

\begin{tabular}{llr}
\hline Gum conc. $(\% \mathbf{w} / \mathbf{v})$ & \multicolumn{2}{c}{ Viscosity of emulsion (mPa. s) } \\
\cline { 2 - 3 } & \multicolumn{1}{c}{ Acacia gum } & \multicolumn{1}{c}{ Afzelia gum } \\
\hline 1 & $14.64 \pm 0.23^{\mathrm{a}}$ & $47.49 \pm 2.09^{\mathrm{a}}$ \\
2 & $14.94 \pm 0.35^{\mathrm{a}}$ & $89.87 \pm 5.33^{\mathrm{b}}$ \\
3 & $15.84 \pm 0.41^{\mathrm{a}}$ & $141.90 \pm 6.43^{\mathrm{c}}$ \\
5 & $16.08 \pm 0.95^{\mathrm{a}}$ & $226.30 \pm 6.53^{\mathrm{d}}$ \\
10 & $23.56 \pm 1.63^{\mathrm{b}}$ & $668.90 \pm 11.65^{\mathrm{e}}$ \\
\hline
\end{tabular}

$\mathrm{N}=3$, Results are expressed as mean \pm SEM, For each column, same letter code means no significant difference at $p<0.05$. 
The conditions of liquid paraffin emulsions containing different concentrations of acacia and afzelia gums after $5 \mathrm{~d}$ of storage are shown in table 5 . Coalescence of the oil globules (cracking) was observed with emulsions containing $5 \% \mathrm{w} / \mathrm{v}$ acacia gum and below.
It was also observed with emulsions containing $1 \% \mathrm{w} / \mathrm{v}$ afzelia gum while different levels of creaming were observed with emulsions containing $2 \% \mathrm{w} / \mathrm{v}$ afzelia gum and above.

Table 5: Conditions of liquid paraffin emulsions containing different gum concentrations after $5 \mathrm{~d}$ of storage

\begin{tabular}{lll}
\hline Gum conc. $(\% \mathbf{w} / \mathbf{v})$ & Condition of emulsion & \\
\cline { 2 - 3 } & Acacia gum & Afzelia gum \\
\hline 1 & Cracked & Cracked \\
2 & Cracked & $36 \%$ creamed \\
3 & Cracked & $16 \%$ creamed \\
5 & Cracked & $4 \% \mathrm{creamed}$ \\
10 & $28 \%$ creamed & No creaming \\
\hline
\end{tabular}

The properties of emulsions containing different emulsifier blends are shown in table 6 . There was no significant difference in the density of emulsions formulated with the different blends of tween 80 and afzelia gum. The viscosity increased and the creaming index decreased with increase in the proportion of afzelia gum.

Table 6: Properties of emulsions containing different emulsifier blends

\begin{tabular}{lllll}
\hline \multirow{2}{*}{ S. No. } & Emulsifier blend & Density & Viscosity & Condition of emulsion after 5 d of storage \\
\cline { 2 - 4 } & Tween 80: Afz gum & $\mathbf{( g / \mathbf { c m } ^ { \mathbf { 3 } } \mathbf { ) }}$ & $\mathbf{( m P a . ~} \mathbf{)}$ & \\
\hline 1 & $5: 1$ & $1.08 \pm 0.02^{\mathrm{a}}$ & $10.62 \pm 0.45^{\mathrm{a}}$ & $48.00 \%$ creamed \\
2 & $2: 1$ & $1.08 \pm 0.03^{\mathrm{a}}$ & $20.78 \pm 0.37^{\mathrm{b}}$ & $46.33 \%$ creamed \\
3 & $1: 1$ & $1.07 \pm 0.02^{\mathrm{a}}$ & $60.48 \pm 1.43^{\mathrm{c}}$ & $43.67 \%$ creamed \\
4 & $1: 2$ & $1.06 \pm 0.03^{\mathrm{a}}$ & $98.20 \pm 2.33^{\mathrm{d}}$ & $32.67 \%$ creamed \\
5 & $1: 5$ & $1.06 \pm 0.03^{\mathrm{a}}$ & $124.80 \pm 3.03^{\mathrm{e}}$ & $25.33 \%$ creamed \\
\hline
\end{tabular}

$\mathrm{N}=3$, Results are expressed as mean \pm SEM, For each column, same letter code means no significant difference at $p<0.05$.

\section{DISCUSSION}

Even though there was no significant difference in the densities of emulsions containing different concentrations of afzelia gum and those containing acacia gum, the densities of emulsions containing afzelia gum were generally lower than those containing the same concentration of acacia gum. The density of liquid paraffin oil which is $0.80 \mathrm{~g} / \mathrm{cm}^{3}[10]$ is lower than the density of each of the emulsions. The difference between the density of emulsion containing afzelia gum and the density of paraffin oil is smaller than the difference between the density of emulsion containing acacia gum and the density of paraffin oil for all the emulsifier concentrations used. Besides, the work of Ibezim et al. [11] showed that the density of dispersion of afzelia gum is lower than the density of dispersion of same concentration of acacia gum. Instability of an emulsion is directly related to the difference between the density of the dispersion medium and that of the dispersed phase [2]. Therefore, emulsions containing afzelia gum might be more stable compared to those containing acacia gum.

According to Billany, hydrophilic colloids are viscosity enhancers; and this character is part of their emulsifying properties [2]. It was also stated that high viscosity is needed for stability of emulsions and that the viscosity of the continuous phase is directly related to the stability of the emulsion [2]. Dispersion of afzelia gum has higher viscosity compared to that of the same concentration of acacia gum [11]. Therefore, better stability observed with emulsions containing afzelia gum could be linked to the higher viscosity observed with the gum as an emulsifier.

Concentrations of 1-5 \% w/v acacia gum are unsuitable for the formulation of liquid paraffin emulsions as cracking was observed with all these emulsions. The relatively higher density and lower viscosity of dispersions of acacia gum are contributing factors to the instability of these emulsions. Besides, it is recommended that emulsions containing mineral oil as liquid paraffin and acacia should be such that ratio of oil: water: gum be $3: 2: 1$ in the primary emulsion. Considering the concentrations of 1-5 \% w/v acacia gum in the emulsions, the proportion of acacia gum was inadequate. Inadequate quantity of emulsifying agent is one of the known causes of cracking [10]. Hence, the observed cracking of emulsions containing this range of concentrations of acacia gum was not unexpected. The concentration of $10 \% \mathrm{w} / \mathrm{v}$ acacia gum complies with the ratio $3: 2: 1$ (oil: water: gum) in the primary emulsion formula, hence, the relative stability of the emulsion formulated with this quantity of acacia gum.

The emulsion containing $3 \% \mathrm{w} / \mathrm{v}$ afzelia gum is comparable with that containing $10 \% \mathrm{w} / \mathrm{v}$ acacia gum. Therefore, afzelia gum is about three times better than acacia gum in terms of emulsification. Its pronounced emulsion stabilization can also be linked to its protein fraction. Gel permeation chromatography of afzelia gum shows a protein-rich fraction [12] and proteins have been implicated in the enhanced surface activity of gums [13]. Since $3 \% \mathrm{w} / \mathrm{v}$ afzelia gum is comparable with $10 \% \mathrm{w} / \mathrm{v}$ acacia gum, the former could be suitable for incorporation into primary emulsion formula (oil: water: gum) as 4:2:0.3, 3:2:0.3 and 2:2:0.3 for fixed oil, mineral oil and volatile oil respectively.

The ability of afzelia gum to form oil-in-water emulsion type is in agreement with the previous work [5] where afzelia gum was found to have HLB value of 9.74 which is within the range of $8-16$, the HLB values of oil-in-water emulsifiers [14]. Applications of oil-in-water emulsification include the formulation of fats and oils for oral administration, formulation of oils for intravenous administration and formulation of water-soluble drugs for topical application. The oil-in-water emulsions for oral administration are more pleasant to take in this form, those for intravenous use have good flow and those for topical administration do not have a greasy texture and are easily washed from skin surfaces [2].

There was no significant difference in the densities of emulsions containing different emulsifier blends (table 6). Hence, the contributions of afzelia gum and tween 80 to the density of the dispersion medium are not significantly different. The observed increase in viscosity of emulsion with an increase in the proportion of afzelia gum shows that afzelia gum has better ability to increase the viscosity of the dispersion medium. The increase in viscosity of emulsion with an increase in the proportion of afzelia gum has a direct relationship with increase in the stability of emulsion which manifested as a decrease in creaming index. 


\section{CONCLUSION}

The effects of afzelia gum and acacia gum on the density of liquid paraffin emulsion are not significantly different, but the former is a better viscosity enhancer. Liquid paraffin emulsion containing $3 \% \mathrm{w} / \mathrm{v}$ afzelia gum is comparable with the emulsion containing $10 \% \mathrm{w} / \mathrm{v}$ acacia gum in term of stability. Hence, the experimented gum could be used at onethird of the concentration of acacia gum to achieve emulsions of similar stability. It is a good alternative to acacia gum as an emulsifying agent.

\section{CONFLICT OF INTERESTS}

Declared none

\section{REFERENCES}

1. Mahmud HS, Oyi AR, Allagh TS. Evaluation of the suspending properties of Khaya senegalensis gum in paracetamol suspension. Niger J Pharm Sci 2009;8:128-34.

2. Billany MR. Suspensions and emulsions. In: Aulton ME. editor. The design and manufacture of medicine. $3^{\text {rd }}$ ed. Philadelphia: Churchill Livingstone, Elsevier; 2007. p. 383-405.

3. Chaudhari SP, Akuskar G, Salvankar SS, Bangar J. Evaluation of suspending and emulsifying properties of Citrullus lanatus seeds gum. Asian J Pharm Clin Res 2014;7:181-5.

4. Builders PF, Chukwu C, Obidike I, Builders MI, Attama AA, Adikwu MU. A novel xyloglucan gum from the seed of Afzelia africana se pers. Some functional and physiochemical properties. Int J Green Pharm 2009;3:112-8.

5. Olorunsola EO, Bhatia PG, Tytler BA, Adikwu MU. Physicosurface properties of afzelia and prosopis hemicellulosic gums: potential surface active agents. IOSR J Pharm Biol Sci 2015;10(4, Suppl 3):1-7.

6. Okorie O, Ibezim CNE, Nwachukwu N. Evaluation of suspending properties of a natural hydrocolloid from Afzelia africana. J Pharm Res 2011;10:112-5.
7. Asantewa Y, Ofori-Kwakye K, Kipo SL, Efsiapa-Boamah V, Johnson R. Investigation of emulsifying and suspending potential of cashew tree gum in pharmaceutical formulations. Int J Pharm Pharm Sci 2011;3:215-9.

8. Momoh MA, Adikwu MU. Determination of hydrophilelipophile balance (HLB) of Bovine mucin for possible emulsifying properties. Animal Res Int 2008;5:840-2.

9. Lachman L, Liberman HA. The theory and practice of industrial pharmacy. Special Indian edition. New Delhi: CBS Publisher and Distributors; 2009. p. 479-94, 502-31.

10. Reilly Jr WJ. Pharmaceutical excipients. In: Felton LA. editor. Remington-Essentials of Pharmaceutics. London, United Kingdom: Pharmaceutical Press; 2013. p. 683-704.

11. Ibezim EC, Khanna M, Singh S, Uzuebenam CE. Afzelia africana seed gum: potential binder for tablet formulations. J Phytomed Ther 2006;11:38-48.

12. Nwokocha LM, Williams PA. Evaluating the potential of Nigeria plants as a source of industrial hydrocolloids. In: Williams PA, Philips GO. editors. Gums and stabilizers for the food industry 16. Great Britain: Royal Society of Chemistry Publishing; 2012. p. 27-44.

13. Golkar A, Nasirpour A, Keramat J, Desobry S. Emulsifying properties of Angum gum (Amygdalus scoparia Spach) conjugated '-Lactoglobulin through Maillard type reaction. Int J Food Properties 2015;18:2042-55.

14. Attwood D. Disperse systems. In: Aulton ME. editor. The Design and Manufacture of Medicine. $3^{\text {rd }}$ ed. Philadelphia: Churchill Livingstone, Elsevier; 2007. p. 70-98.

\section{How to cite this article}

- Emmanuel O Olorunsola, Stephen O Majekodunmi. Emulsifying properties of afzelia gum in liquid paraffin emulsion. Int J Pharm Pharm Sci 2016;8(11):195-198. 